\title{
Paracoccidioides brasiliensis: phylogenetic and ecological aspects
}

\author{
Eduardo Bagagli - Raquel C. Theodoro • \\ Sandra M. G. Bosco $\cdot$ Juan G. McEwen
}

Received: 27 June 2007 / Accepted: 13 August 2007

(C) Springer Science+Business Media B.V. 2007

\begin{abstract}
The knowledge on the biological aspects of Paracoccidioides brasiliensis has evolved greatly since the first description of the disease in 1908. From the pioneers, who were able to clearly demonstrate the fungal nature of the agent, to the recent genomic era, important advances have been achieved. $P$. brasiliensis is a true fungus, belonging to the Ascomycetous Division, although its sexual phase has not been demonstrated morphologically. A better understanding of the fundamental aspects of the agent, especially its phylogeny and evolutionary history, will provide us with valuable insights allowing a better comprehension of the disease and our capacity to deal with the problem. Concerning the fungus's ecology, although some progress had been observed, the ecological niche of the pathogen has not been determined yet. The aim of the present review is to focus on the biological aspects of $P$. brasiliensis from an evolutionary point of view, addressing the fungus's phylogenetic aspects, in those special points that might be relevant for the pathogen/ host interactions, the biological forces that have been acting on its origin and maintenance of virulence, as
\end{abstract}

E. Bagagli $(\bowtie)$ - R. C. Theodoro - S. M. G. Bosco Universidade Estadual Paulista, Campus de Botucatu UNESP, Botucatu, SP, Brazil e-mail: bagagli@ibb.unesp.br

J. G. McEwen

Universidad de Antioquia, Medellin, Colombia well as in determining the fungus's ecology and epidemiology.

Keywords Paracoccidioides brasiliensis . Paracoccidioidomycosis · Ecology ·

Evolution · Phylogeny

\section{Phylogenetic aspects of Paracoccidioides brasiliensis}

The study of phylogeny with the aim of determining the correct position of a pathogen in the tree of life is important not just for defining its correct taxonomic status but also for indicating the main evolutionary tendencies and biological forces acting upon the species. For a long time, $P$. brasiliensis was considered an imperfect fungus due to our failure to detect its sexual or teleomorphic phase. In recent years, with the advances of molecular techniques, $P$. brasiliensis has been placed in the family Onygenaceae (Order Onygenales, Ascomycota), in a common group with Blastomyces dermatitidis, Coccidioides immitis, Histoplasma capsulatum and Lacazia loboi [1-3]. More recently, a clade distinct from Onygenaceae sensu lato has been proposed as a new family (Onygenales, Ajellomycetaceae) to encompass the monophyletic group Ajellomyces, which includes the anamorph genera Blastomyces, Emmonsia, Histoplasma, and Paracoccidioides [4].

This fungal group (Onygenales, Onygenaceae sensu lato) presents several common mycological 
and ecological features such as dimorphism (filamentous and yeast forms in the saprobic and pathogenic conditions, respectively), arthroconidia (the airborne infective propagula), restricted geographic distribution, and some affinity for animal wastes such as feces and uric acid [4, 5]. In the same Onygenales Order, but in another natural branch, we find the family Arthrodermataceae that contains the dermatophytic fungi, certainly the most prevalent infectious agents for humans and other animals throughout the world [6]. This last group has developed the ability to degrade keratin, a highly insoluble protein, from skin, nails, and hair, a feature that has been considered an innovative key in the evolution of animal dermatopathogenicity [7, 8], probably developed during the association with burrowing and denning animals $[6,9]$.

Molecular phylogenetic and phylogeographic studies have also indicated that the several species members of the Onygenaceae (sensu lato) may have originated in the Americas around 3-20 million years ago [10], and that some of the most important ones, such as Histoplasma and Paracoccidioides species, almost certainly evolved in South America, prior to the connection of the Panamanian Isthmus [11, 12]. In addition, it is becoming clear that this group of fungal pathogens has evolved to a lifestyle associated with animal hosts, though with the maintenance of the saprobic phase in the physical environment $[4,13]$.

\section{Origin and maintenance of $\boldsymbol{P}$. brasiliensis' virulence}

What biological forces make a fungus capable of adapting to a mammal host in a pathogenic relationship? Taking into account that $P$. brasilensis might have been associated with animal hosts for a long time, what kinds of genetic changes could have been occurring?

Some physiological and morphological changes which are supposed to facilitate the pathogenic lifestyle and are commonly referred to as virulence factors, have been traditionally observed in pathogenic fungi [14]. Some cell-wall compounds such as $\alpha$-(1,3)-glucan, adhesion molecules, and enzymes (proteinases, lipases, phospholipases), considered important for fungal nutrition and invasion of animal tissues, have been observed in P. brasiliensis and in other pathogenic dimorphic fungi [15-20]. P. brasiliensis immunodominant antigen, GP43, also has been considered a virulence factor, since as originally mentioned, it supposedly had proteolytic effects on collagen, elastin and casein [21], as well as a confirmed adhesion property to laminin [22].

Both thermo-tolerance and dimorphism have also been considered important virulence factors, since the body temperature of most vertebrate hosts is relatively high [14]. In fact, certain hypotheses generated on the origin of endothermy in animals consider it a protective factor against infectious diseases, in particular fungal diseases. Given that most fungal species grow best at ambient temperatures, the high body temperature of endothermic animals must provide a thermal barrier for protection against infection with a large number of fungi. Few fungal species can survive at high temperatures, but this tolerance seems to be common among the pathogenic dimorphic fungi, such as Cryptococcus neoformans, H. capsulatum and Sporothrix schenckii. It is known for example, that $C$. neoformans var. gatii isolates that do not present satisfactory growth at $37^{\circ} \mathrm{C}$ are not able to produce fatal infection in rats [23, 24]. Lowvirulence isolates of $H$. capsulatum take a longer time to convert from the mycelial to yeast form than those possessing high virulence [25].

Traditionally, infection has been considered a 'blind alley' for the dimorphic pathogenic fungal species, with no biological meanings, mainly because these infections are not contagious from host to host. If an animal host is not required, how could the complex traits of virulence originate in this group of pathogens? In order to answer this question, Casadevall et al. [26] and Steenbergen and Casadevall [27] have proposed some original ideas such as the concept of 'ready-made' virulence or 'dual-use' virulence factors. They have studied the role of some virulence factors in $C$. neoformans saprobic phase concluding that soil conditions (such as the competition with other microorganisms) would exert selective pressure, thus originating some of the features that under parasitic circumstances would result in virulence and pathogenicity, suggesting, therefore, that in $C$. neoformans virulence factors have a dual use. According to these ideas, such virulence factors have emerged in soil and/or in other environmental conditions, so that virulence was 'ready-made' when these fungi infect a vertebrate 
host for the first time. The main attraction of these ideas resides in the possibility of testing them experimentally, for example, by putting together the fungus with some phagocytic soil amoebas in the same tube. That is what has been done, not just with $C$. neoformans, but also with the dimorphic fungi $B$. dermatitidis, H. capsulatum, and S. schenckii [28]. While these pathogenic fungi survived and killed the amoebas, a nonpathogenic fungus such as Saccharomyces cerevisiae and the human-adapted fungus Candida albicans were killed by the protozoan. Furthermore, it was also observed that an avirulent strain of H.capsulatum recovered its virulence after being co-cultured with the amoeba Acanthamoeba castellani [28].

According to Lederberg [29-31], in the hostpathogen relationship, more important than the acquisition of virulence genes was the biological mechanisms that contribute to mitigating virulence, such as auxotrophy that allow the pathogen to grow slowly. This assumption has been clearly observed in several species of Mycobacteria, in which the subject has been well documented and also confirmed by comparative genomic studies [32-34]. For example, $M$. leprae has undergone an extensive reductive evolution with half of its genome now occupied by pseudogenes, instead of the homologous functional genes found in the related species M. tuberculosis [32]. This gene deletion and decay has eliminated many metabolic activities of the leprosy bacillus, probably because their functions are no longer required in an obligate intracellular parasite with a highly specialized niche [32]. The same process has been detected in $M$. ulcerans, the causative agent of a severe necrotic ulceration, named Buruli ulcer, when its genome was compared to the nearest related species M. marinum [34].

Comparative genomics have also proven very powerful in providing insights into the strategies that fungal pathogens have produced in order to adapt to specific habitats and niches. For example, by comparing the genomes of Pneumocystis carinii (an opportunistic extracellular lifestyle) with Saccharomyces cerevisiae (a free-living lifestyle) and the microsporidia Encephalitozoon cuniculi (an obligate intracellular lifestyle) it could be seen that the genome size, gene number, and metabolic function decreased as the organisms became more dependent on their hosts [35]. The several dimorphic pathogenic fungi tend to present a prototrophic condition when growing in the saprobic mycelial phase, while specific nutrients (auxotrophy) are required when growing in the yeast form at elevated temperatures that mimic the pathogen's condition. Could the different species of dimorphic fungi be occurring in different stages of co-evolution with their hosts and in this manner presenting distinct degrees (or level) of auxotrophy/prototrophy and a general tendency to reduce their saprobe phase, as result of genome downsizing or gene silencing? As already mentioned, $L$. loboi is biologically closely related to $P$. brasiliensis, and certainly also an Ajellomycetaceae member. This pathogen grows only under tissue conditions behaving as a biotrophic obligate microorganism, generally in a chronic condition and producing a high amount of catenulate yeast cells $[3,36]$. A comparative genomic study of $P$. brasiliensis and $L$. loboi would be welcomed and could certainly clarify the situation if the same supposed evolutionary tendency of decaying genes is occurring here. It would also indicate whether genomic signatures and different stages of host association under auxotrophic/prototrophic conditions might reflect the niche occupation resulting in different forms of infection. For example, while $P$. brasiliensis presents a saprobic phase, probably in a restricted and reduced form, could $L$. loboi have completely lost its saprobic mycelial form, being transmitted only from host to host?

The biological significance of animal hosts for pathogenic fungi has not been well addressed until now. Concerning fungal dissemination, there is some experimental and indirect evidence that animals infected systemically, with $C$. immitis for example, would disseminate the fungus to the environment through their carcasses [37, 38]. In fact, the distribution and structure of $C$. immits populations have revealed a recent dispersion of this pathogen to South America through human migration [39]. There is also evidence that the speciation process in species members of the Arthrodermataceae family has been strongly shaped by animal hosts [6, 9]. In fact, when a fungal species acquires certain adaptation capacities to infect and colonize a host, this situation seems to open new opportunities in terms of expanding its traditional ecological niche and exerting pressures for speciation [40]. In some cases, the host selective pressure on the pathogen population can be strong 
enough to be considered an allopatric speciation factor (different hosts could be similar to different geographic areas). This speciation phenomenon has been observed, for example, in the genus Pneumocystis that comprises non-cultivable, highly diversified fungal pathogens dwelling in the lungs of mammals. Although the genus shows little difference under light microscopy, DNA sequencing studies revealed numerous host-specific species, such as $P$. jirovecii in humans, $P$. carinii and $P$. wakefieldiae in rats, $P$. murina in mice, and $P$. oryctolagi sp. nov. from Old World rabbits [41]. And what does animal infection mean for $P$. brasiliensis? Could it contribute to fungal dissemination at present, and from a longer evolutionary perspective, could it be important for the fungus's adaptation and speciation?

\section{Isolation of $\boldsymbol{P}$. brasiliensis from armadillos and clues about its evolution, habitat and ecological niche}

P. brasiliensis has been isolated only sporadically from soil [42-45], feces of bats, Artibeus lituratus [46], penguins, Pygoscelis adeliae [47], and dog food [48]. The main constraint here is the lack of repeatability of such findings [49]. Furthermore, the disease has a prolonged period of latency and outbreaks have never been observed, making it much more difficult to trace the fungus in its environment.

Epidemiological data clearly indicate the pathogen occurs in localized geographic areas of South and Central America, in cluster conditions [50, 51]. It has now become clear that the recent distribution of the disease is determined not only by the recent ecological factors dictating the fungus's development in nature, but also by the phylogeographic aspects of the pathogen, involving the fungus's evolutionary past, its prolonged relation with hosts and environment, and all associated genetic exchanges [13].

The demonstration of a high incidence of $P$. brasiliensis infection in the nine-banded armadillo, Dasypus novemcinctus, a wild mammal that typically has evolved in South America and lives immersed in soil [52-58], has opened new perspectives for comprehending the pathogen's ecology and evolution. In this animal species and also in the naked-tailed armadillo, Cabassous centralis [59], P. brasiliensis can be isolated regularly. Histopathological analyses in the animal tissues have revealed rare granulomas containing yeast cells of the pathogen [54, 57].

P. brasiliensis isolates obtained from armadillos present a significant variability with regard to virulence, antigen and molecular (RAPD and sequencing of rDNA regions and gp43 gene) profiles [60-63]. This variability does not seem to be related to its hosts, since $P$. brasiliensis isolates from nine-banded armadillo are indistinguishable from clinical ones, indicating that the same "ecopathogenotypes" infect both animals and human [49, 54, 64]. By having a low body temperature, ranging from 32.7 to $35.3^{\circ} \mathrm{C}$ [65], a weak immunological system [66] and constant contact with $P$. brasiliensis in soil, armadillos may infect and acquire the pathogen repeatedly. In fact, when the partial sequences of gp43 gene were studied it became clear that multiple infections occur in the same animal [60, 61]. These data reinforced the previously suggested hypothesis that parasitism could not be considered a blind alley, but rather a two-way street for dimorphic pathogenic fungi, where the preservation of the saprobic form-coupled with a parasitic form in animals-could even contribute to sexual reproduction, by providing proximity of mating types in a protected environment, such as an armadillos' burrow [13].

The armadillo group Dasypodidade and the Ajellomycetaceae fungi are both ancient lineages that may have been cohabiting in the same continental area for periods of 10-20 million years. Thus, one might ask whether the armadillo- $P$. brasiliensis association is an ancient one or, alternatively, if it has occurred only in recent times as the result of human action. The latter scenario should not be excluded, as it seems to have happened with $M$. leprae, which probably originated in Africa and was introduced into the Americas (and into armadillos) less than 500 years ago [33], and the bacteria has been found infecting armadillos naturally in some areas endemic for Hansen's disease [67]. C. immitis also has been isolated from armadillos in the northeast region of Brazil, and as already mentioned, this pathogen has been introduced in South America only recently by human migration $[39,68]$. Thus, in a relative short period of evolutionary time, the bacteria $M$. leprae and the fungus $C$. immitis were able to establish themselves in armadillos indicating that humans may interfere strongly in the recent ecological history of both mentioned pathogens, as well as in all wild 
reservoirs. In order to decide if the relationship of $P$. brasiliensis with armadillos is recent (thousand of years) or an ancient one (millions of year) could be more than a simple intellectual challenge, since it may also point to an important human interference in the fungus's evolution.

For practical purposes, natural infection by $P$. brasiliensis occurring with high frequency in ninebanded armadillos could be used for mapping risk areas of infection. These animals typically present a short home range, the area necessary for them to obtain food and to reproduce, and in this manner, an infected animal indicates that the fungus occurs in the vicinity. Infected armadillos have been observed mainly in shady and disturbed vegetation areas located near small rivers, on soil of both sandy and clayey type, and positive armadillos have also been detected near small urban sites in Botucatu, a hyperendemic area for PCM [55].

The presence of $P$. brasiliensis in soil samples collected from armadillo burrows could be confirmed molecularly, by applying a species-specific Nested PCR, based on ITS-5.8S-ITS2 regions [69]. It is interesting to note that the pathogen could be detected mainly in soil samples collected in the interior of the armadillo burrows [70]. We have adapted this same molecular protocol looking for fungal infection in several other wild mammals accidentally killed on roads [71]. Specific P. brasiliensis DNA amplicons were detected in samples of mesenteric lymph node, spleen, lung, adrenal glands, and kidney of Cavia aperea ("guinea pig"), in lung and liver of Sphiggurus spinosus ("porcupine"), in lungs of Gallictis vittata ("grison") and Procyon cancrivoros ("raccoon"), as well as in several organs of the nine- and seven-banded armadillos (Dasypus septemcinctus), thus indicating that in endemic areas $P$. brasiliensis infection in wild animals, exhibiting a certain systemic dissemination, might be more common than initially supposed. In fact, intradermal tests have also indicated that several wild and domestic animals could be infected by the fungus [72], and PCM disease was recently confirmed to occur in dogs [73, 74].

The correct use of the terms habitat and ecological niche should be incorporated into $P$. brasiliensis literature, both for the sake of clarity and also to avoid considering the pathogen as an anomalous species that does not follow the general ecological principles demanding new terms and neologisms, such as "reservarea" and "microniche". Several pieces of evidence point towards the soil as the most probable saprobic habitat for P. brasiliensis. But more important than discovering the precise location where this pathogen lives would be to determine its ecological niche inside its habitat. The ecological niche is defined not as a location, but as a multidimensional volume possessing certain limits defined by the tolerances and requirements of the organism. So, one habitat is composed of $n$ niches [75]. The modern concept of niche was proposed by Hutchinson in 1957 and it refers to the interaction among the tolerances and needs of the organism with respect to the conditions (abiotic factors, such as light, temperature, etc.) and resources (food, nutrients, meaning the consumed and limited substrate) of the environment [76]. There are uncountable dimensions for an ecological niche of a single determined species. This niche is represented by the tolerance for several conditions and by the need for several resources. So, the ecological niche is considered an n-dimensional hypervolume that limits the species distribution. Although there is a range of abiotic and biotic factors that a particular species could tolerate (the fundamental niche), the species occupies only part of this niche (the effective niche). This occurs because there is competition among different species, thus limiting their distribution across the $n$ dimensions of the niche [77].

It is important to note that the same organism could, in some cases, occupy more than one ecological niche during its life cycle. For example the niche of a juvenile form of an insect is different from that of its adult niche [75]. This clearly occurs in P. brasiliensis and other thermodimorphic pathogenic fungi: during their mycelial saprobic phase these pathogens are under the influence of different conditions and resources, such as frequent changes in temperature and humidity and, additionally, experience competition with other microorganisms. During the yeast pathogenic phase, these fungi should adapt to a different habitat, where they could occupy various niches in the body's internal organs, according to fungal tolerance for several conditions, such as temperature increase, hormonal influences, and response to the immune system (Fig. 1).

Despite the many pieces of information found in the $P$. brasiliensis literature concerning the yeast phase and its parasitic niche-such as the clinical aspects of the disease, the associated immune 


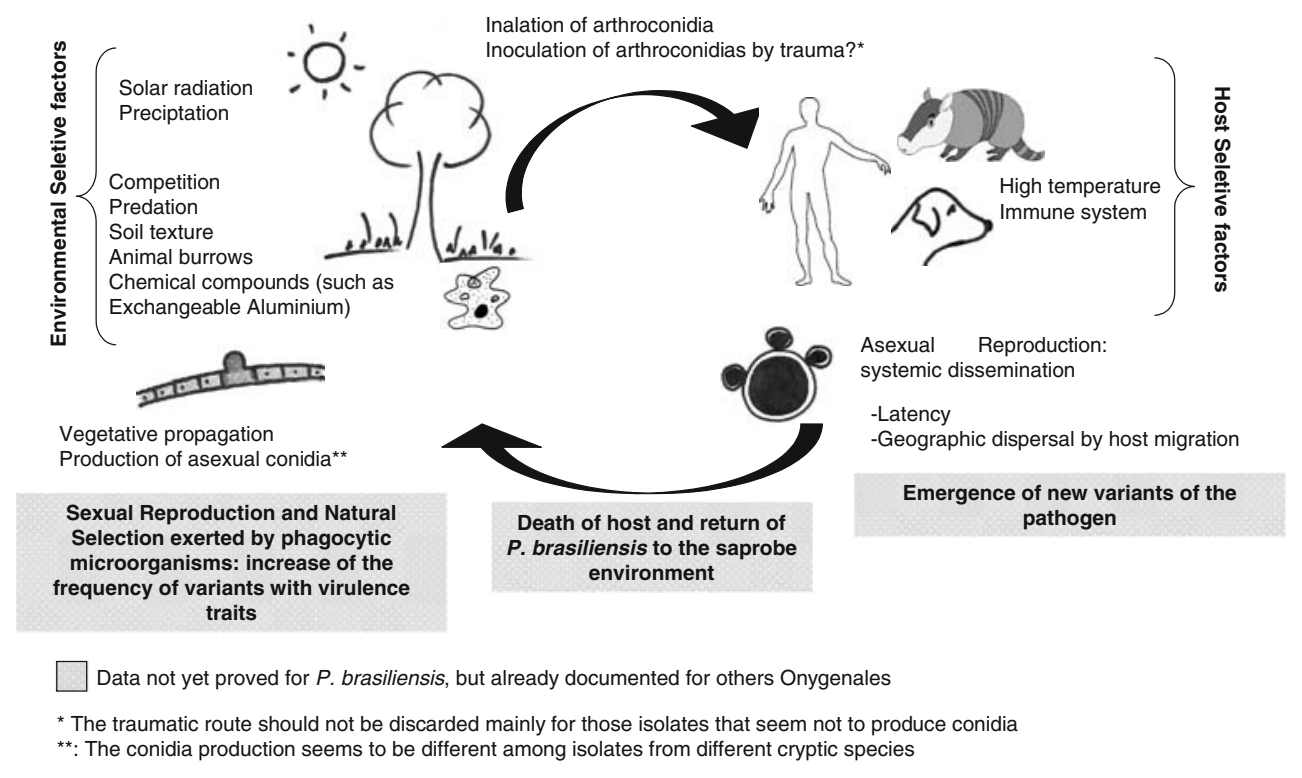

Fig. 1 Hypothetical biological cycle of Paracoccidioides brasiliensis, emphasizing some selective forces that may be acting on its supposed ecological niches, in hosts and in saprobic environments

responses, certain data concerning on natural infection in wild and domesticated animals and also on experimental infection-almost nothing has been published concerning its saprobic niche and its mycelial phase. We have studied $P$. brasiliensis mycelial growth in soils in order to understand how the pathogen interacts with some abiotic factors, such as soil texture and water amount [70]. It was observed that $P$. brasiliensis grows well in both soil textures (clayey and sandy) when the humidity is high (water saturated), presents moderate growth in soil containing medium humidity, and no growth in lowhumidity soil. As expected, the water availability constitutes a limiting factor for fungal growth. In this experimental study, we have also observed that $P$. brasiliensis is unable to grow in some soils containing high amounts of Exchangeable Aluminum $(\mathrm{H}+\mathrm{Al})$ and low Bases Saturation. These results also corroborate some previous reporting on $P$. brasiliensis isolation from armadillos in our endemic area, in which we aimed to address the associated ecological factors [55]. Firstly, positive-culture armadillos were observed living in both in clay and sandy soil; secondly, the frequency of animal infection was heterogeneous in the different counties composing our endemic area; and finally, all armadillos captured in a restricted site (from Pardinho County), where soil analysis had revealed a high concentration of Exchangeable Aluminum, proved to be negative for P. brasiliensis culture.

Many other dimensions of the $P$. brasiliensis saprobic ecological niche, such as, temperature, salt tolerance, interactions with other soil microorganisms, competition for resources and predation by phagocytic microorganism, for example, should be studied. This knowledge would certainly be helpful in discovering the best conditions and resources necessary for fungal development and conidia production in the environment, and would, consequently, aid in determining the circumstances and conditions regulating risks for human infection.

\section{Cryptic species in $P$. brasiliensis: ecological meanings}

Despite the common perception of significant variability in $P$. brasiliensis isolates, for a long time this pathogen has been considered a unique biological entity, mainly because of its characteristic microscopic aspects, both under parasitic and culture conditions. This fact, although well accepted for practical purposes and medical diagnosis, has been challenged by recent findings of the fungus's 
molecular diversity, mainly when subjected to adequate theoretical and operational approaches. This fungus presents many variable phenotypes in growth, mycelial colony, conidia production, mycelia-yeast transition, yeast microscopy (budding, size and shape of cells), virulence, and thermal tolerance [78, 79], as well as in clinical manifestations [80].

Considered a central theme in evolutionary biology, the species concept has been the subject of intense debates and has evolved substantially throughout the years. There are different concepts for species that tend to be applied to different organisms. The morphological recognition of species is based, for example, on phenotypes that are common among the species members and different from other species. However, it is usual to group genetically different organisms into one species, mainly when the target of study is unicellular organisms, in which the detection of morphological differences is extremely hard to obtain when compared to larger, multi-cellular organisms. The most widely accepted concept for the biological recognition of species considers the species to be a reproductive unit that takes into account its interbreeding capacity. However, such recognition does not apply to asexual populations, or even to sexual ones, and it may lead to conflict between the potential and real gene flows. It is important to note that even allopatric species may retain their interbreeding capacity, and furthermore, there is no selection for gene-flow barriers since the species are geographically isolated [81]. The ecological concept of species defines species as a group of individuals that occupy the same niche and this concept is closely connected to the biological one because natural selection will favor the individuals that interbreed only with those that have the same ecological adaptation. It is known that the adaptive value of hybrids could be, in many cases, lower than that of the parental species, which present better competitive adaptations occupying their niches [82]. This concept is also very difficult to apply to microorganisms that have niches defined by their biochemical interactions with the substrate (environmental and host) and, as already discussed, is composed of $n$ dimensions.

The phylogenetic species concept, which detects genetic divergence among populations through multilocus sequence typing by concordance of gene genealogies, seems to be the most appropriate method for fungal species recognition [83]. It permits inference of the reproductive mode of the different divergent species, even without the actual production of sexual structures. Additionally, in a single species, clonal and recombining reproduction can be temporally or spatially separated [81]. Consequently, the failure to detect sexual structure does not signify the absence of such structures. Using this approach, Matute et al. [84, 85] were able to detect three cryptic species in $P$. brasiliensis, from which two are phylogenetic species (PS2, composed of Brazilian and Venezuelan isolates, and PS3, restricted to Colombia) and one is a paraphyletic species ( $\mathrm{S} 1$, which has a wider habitat range across the endemic areas). They also observed that while S1 and PS2 were considered recombining sexual species, PS3 was shown to be clonal. It is interesting to note that S1 and PS2 are sympatric and, despite the fact that they have sexual reproductive attributes, they are reproductively isolated. These data were corroborated by microsatellite analysis of the same isolates used in the previous gene genealogy study [85]. According to the analysis of the $18 \mathrm{~S}$ region, the time of divergence between PS2 and PS3 is about 8.04-8.37mya [86]. The authors suggested that the speciation of PS3, geographically restricted to Colombia, could be attributed to dispersal or some other event leading to genetic isolation of PS3 from S1 (allopatric speciation). The other speciation event that originated the PS2 species is still poorly understood. It is possible that S1 and PS2 are the result of sympatric speciation. This type of speciation has been a source of controversies, since there are, apparently, no environmentally and/or geographically selective forces. The initial step for a sympatric speciation occurrence is the existence of polymorphism, which is much more abundant in recombining species, such as in PS2 and S1. For example, two forms of one single species can be adapted to different resources and/or conditions in their niche. If the interbreeding between them is not positively selected because of the low adaptive value of the hybrids, there will be a reinforcement of reproductive isolation by natural selection [40]. This reinforcement is very important because speciation involves not only divergence, but also maintenance, mainly when the derived species coexist [81]. Dettman et al. [87] showed how these barriers to inter-species interbreeding may be 
different between allopatric and sympatric species of Neurospora; they observed a higher reproductive success for allopatric heterospecific pairings than for sympatric ones.

The ability to coexist in the same habitat is greater between species with sexual reproduction, since they can evolve to occupy different ecological niches. In fact, if the species are genetically separated, they may accumulate some morphological differences, which could result in the occupation of new ecological niches, or in different strategies for survival in the saprobic or host environments. Theodoro et al. [79] studied the mycelia-to-yeast (M-L) phase transition in isolates from $\mathrm{S} 1$ and PS2 species and its relation to the partial sequencing and expression of the hsp70 gene. Although this gene is considered a wellconserved one, its sequence allowed the separation of our isolates into two groups that correspond to the S1 and PS2 species. Some microscopic features of these isolates were shown to be important candidates for a morphological differentiation between these two species. The isolates $\mathrm{T} 10$ and $\mathrm{Bt} 84$, representing the PS2 species, seemed to have elongated yeast cells and presented a slower M-L transition than the other isolates. In addition to these data, Terçarioli et al. [70], studying the fungal growth on Soil Extract Agar, observed that most isolates, except T10 and Bt84, were able to produce, on a large scale, arthoconidia in this medium. Could these differential characteristics be an indication that these two sympatric species may have also occupied different niches in nature? It seems that the genotypes from the PS2 species occur less frequently than the genotypes from the $\mathrm{S} 1$ species, both from humans and armadillos [82]. Particularly in our armadillo isolates, all from the same hyperendemic area, this proportion was 1:9. Theodoro et al. [79] have speculated whether the few cases of fungal isolation from PS2 species could be explained by the low capacity or non-production of conidia, the infecting propagula, as well as if these PS2 genotypes could be associated with infection by the traumatic route, instead of the respiratory one. More studies that include a larger number of isolates from the three species are still necessary for the identification of morphological, molecular, physiological, clinical and ecological features associated with the species-specific genotypes of $P$. brasiliensis.

\section{Conclusions and perspectives}

$P$. brasiliensis is biologically related to a fungal group that typically has evolved in association with mammal hosts. Besides having the ability to multiply in deep host tissues, the fungus has also preserved its competence to grow as a saprobe in open nature, though in some restricted environments. The fungus presents a certain degree of genetic variability, now well addressed by molecular tools, that indicates the existence of at least three cryptic species infecting human and animals. The association of each species type with distinct profiles of clinical manifestation and response to the treatment and epidemiological patterns, seems to be just a question of time. Since the collection of functional genes reflects the organism lifestyle, comparative genomic studies in this group will also provide innovative clues about the fungus's biology. This new genomic era is creating the conditions to advance the complementary concepts of species and of the ecological niche of P. brasiliensis in the same convergence route.

Aknowledgments We thank the São Paulo State Research Foundation (Fapesp) for the financial support (Grant number 06/03597-4) and Dr Angela Restrepo for helpful discussions and revising the English text.

\section{References}

1. Bialek R, Ibricevic A, Fothergill A, Begerow D. Small subunit ribosomal DNA sequence shows Paracoccidioides brasiliensis closely related to Blastomyces dermatitidis. J Clin Microbiol 2000;38:3190-3.

2. San Blas G, Nino-Vega G, Iturriaga T. Paracoccidioides brasiliensis and paracoccidioidomycosis: molecular approaches to morphogenesis, diagnosis, epidemiology, taxonomy and genetics. Med Mycol 2002;40:225-42.

3. Herr RA, Tarcha EJ, Taborda PR, Taylor JW, Ajello L, Mendoza L. Phylogenetic analysis of Lacazia loboi places this previously uncharacterized pathogen within the dimorphic Onygenales. J Clin Microbiol 2001;39:309-14.

4. Untereiner WA, Scott JA, Naveau FA, Sigler L, Bachewich J, Angus A. The Ajellomycetaceae, a new family of vertebrate-associated Onygenales. Mycologia 2004;96:812-61.

5. Currah RS. Taxonomy of the Onygenales: Arthrodermataceae, Gymnoascaceae, Myxotrichaceae and Onygenaceae. Mycotaxon 1985;24:1-216.

6. Weitzman I, Summerbell RC. The dermatophytes. Clin Microbiol Rev 1995;8:240-59.

7. Leclerc MC, Philippe H, Gueho E. Phylogeny of dermatophytes and dimorphic fungi based on large subunit 
ribosomal RNA sequence comparisons. J Med Vet Mycol 1994;32:331-41.

8. Scott JA, Untereiner WA. Determination of keratin degradation by fungi using keratin azure. Med Mycol 2004;42(3):239-46.

9. Kaszubiak A, Klein S, de Hoog GS, Gräser Y. Population structure and evolutionary origins of Microsporum canis, M. ferrugineum and M. audouinii. Infect Genet Evol 2004;4(3):179-86.

10. Fisher MC, Koenig G, White TJ, Taylor JW. A test for concordance between the multilocus genealogies of genes and microsatellites in the pathogenic fungus Coccidioides immitis. Mol Biol Evol 2000;17(8):1164-74.

11. Kasuga T, Taylor JW, White TJ. Phylogenetic relationships of varieties and geographical groups of the human pathogenic fungus Histoplasma capsulatum Darling. J Clin Microbiol. 1999;37:653-63.

12. Kasuga T, White TJ, Koenig G, McEwen J, Restrepo A, Castañeda E, Lacaz CS, Heins-Vacari E, Freitas R, Zancope-Oliveira RM, Qin Z, Negroni R, Carter DA, Mikami Y, Tamura M, Taylor ML, Miller GF, Poonwan N, Taylor JW. Phylogeography of the fungal pathogen Histoplasma capsulatum. Mol Ecol 2003;12:3383-401.

13. Bagagli E, Bosco SMG, Theodoro RC, Franco M. Phylogenetic and evolutionary aspects of Paracoccidioides brasiliensis reveal a long coexistence with animal hosts that explain several biological features of the pathogen. Infect Genet Evol 2006;6:344-51.

14. Kurokawa CS, Sugizaki MF, Peraçoli MTS. Virulence factors in fungi of systemic mycoses. Rev Inst Med Trop S Paulo 1998;40(3):125-35.

15. San-Blas G, Vernet D. Induction of the synthesis of cell wall $\alpha$-1,3-glucan in the yeast like form of Paracoccidioides brasiliensis strain IVIC $\mathrm{Pb} 9$ by fetal calf serum. Infect Immun 1977;15:897-902.

16. Vartivarian SE. Virulence and nonimmune pathogenic mechanisms of fungi. Clin Infect Dis 1992;14:30-6.

17. Jimenez-Lucho V, Ginsburg V, Krivan HC. Cryptococcus neoformans, Candida albicans and other fungi bind specifically to the glycosphingolipid lactosylceramide (Gal $\beta 1$ $4 \mathrm{Gl} \beta 1-1 \mathrm{Cer})$, a possible adhesion receptor for yeasts. Infect Immun 1990;58:2085-90.

18. Klein BS, Hogan LH, Jones JM. Immunological recognition of a 25-amino acid repeat arrayed in tandem on a major antigen of Blastomyces dermatitidis. J Clin Invest 1993;92:330-7.

19. Odds FC. Candida albicans proteinase as a virulence factor in the pathogenesis of Candida infections. Zbl Bakt Hyg Ser A 1985;260:539-42.

20. Ruchel R. Cleavage of immunoglobulin by pathogenic yeast of the genus Candida. Microbiol Sci 1986;3:316-9.

21. Mendes-Gianinni MJS, Moraes RA, Ricci TA. Proteolytic activity of the 43,000 molecular weight antigen secreted by Paracoccidioides brasiliensis. Rev Inst Med Trop S Paulo 1990;32:384-5.

22. Vicentini AP, Gesztesi J, Gesztesi JL, Franco MF. Binding of Paracoccidioides brasiliensis to laminin through surface glycoprotein gp43 leads to enhancement of fungal pathogenesis. Infect Immun 1994;62:1465-9.

23. Kwon-Chung KJ. Comparison of isolates of Sporotrix schenckii obtained from fixed cutaneous lesions with isolates from other types of lesions. $\mathbf{J}$ infect Dis 1979;139:424-31.

24. Rhodes JC. Virulence factors in fungal pathogens. Microbiol Sci 1988;5:252-4.

25. Medoff G, Maresca B, Lambowitz AM, Kobayashi G, Painter A, Sacco M, Carratu L. Correlation between pathogenicity and temperature sensitivity in different strains of Histoplasma capsulatum. J Clin Invest 1986;78:1638-47.

26. Casadevall A, Steenbergen JN, Nosanchuk JD. "Ready made" virulence and "dual use" virulence factors in pathogenic environmental fungi - the Cryptococcus neoformans paradigma. Curr Opin Microbiol 2003;6:332-7.

27. Steenbergen JN, Casadevall A. The origin and maintenance of virulence for the pathogenic fungus Cryptococcus neoformans. Microb Infect 2003;5:667-75.

28. Steenbergen JN, Nosanchuk JD, Malliaris SD, Casadevall A. Interaction of Blastomyces dermatitidis, Sporothrix schenckii, and Histoplasma capsulatum with Acanthamoeba castellanii. Infect Immun 2004;72:3478-88.

29. Lederberg J. Infectious agents, hosts in constant flux. Evolutionary perspectives are indispensable for studying the dynamics of infectious diseases and antibiotic resistance. ASM News 1999;65:18-22.

30. Lederberg J. Parasites face a perpetual dilemma. The relationships between pathogens and hosts must become delicate balances of adaptation if both parties are to survive. ASM News 1999;65:77-85.

31. Lederberg J. Paradoxes of the host-parasite relationship. Applying the injunction "thou shalt not kill" to pathogens brings surprising insights about how they adapt to hosts. ASM News 1999;65:811-6.

32. Cole ST, Supply P, Honore N. Repetitive sequences in Mycobacterium leprae and their impact on genome plasticity. Lepr Rev 2001;72(4):449-61.

33. Monot M, Honore N, Garnier T, Araoz R, Coppée JY, Lacroix C, Sow S, Spencer JS, Truman RW, Williams DL, Gelber R, Virmond M, Flageul B, Cho SN, Ji B, PanizMondolfi A, Convit J, Young S, Fine PE, Rasoloto V, Brennan PJ, Cole ST. On the origin of leprosy. Science 2005;308:1040-2.

34. Stinear TP, Hong H, Frigui W, Pryor MJ, Brosch R, Garnier T, Leadley PF, Cole ST. Common evolutionary origin for the unstable virulence plasmid pMUM found in geographically diverse strains of Mycobacterium ulcerans. J Bacteriol 2005;187(5):1668-76.

35. Cushiom MT. Comparative genomics of Pneumocystis carinii with other protists: implications for life style. J Eukaryot Microbiol 2004;51(1):30-7.

36. Mendoza L, Ajello L, Taylor JW. The taxonomic status of Lacazia loboi and Rhinosporidium seeberi has been finally resolved with the use of molecular tools. Rev Iberoam Micol 2001;18(3):95-8.

37. Maddy KT, Crecelius HG. Establishment of Coccidioides immitis in negative soils following burial of infected animals and animal tissues. In: Ajello L, editor. Coccidioidomycosis. Tucson: University of Arizona Press, 1967. p. 309-12.

38. Lacy GH, Swatek FE. Soil ecology of Coccidioides immitis at American middens in California. Appl Microbiol 1974;27:379-88. 
39. Fisher MC, Koening GL, White TJ, San-Blas G, Negroni R, Alvarez IG, Wanke B, Taylor JW. Biogeographic range expansion into South America by Coccidioides immitis mirrors New World patterns of human migration. Proc Natl Acad Sci USA 2001;98(8):4558-62.

40. Coyne JA, Orr HA. Speciation. Sunderland, MA: Sinauer Associates, 2004.

41. Dei-Cas E, Chabe M, Moukhlis R, Durand-Jolly I, Aliouat el M, Stringer JR, Cushion M, Noel C, de Hoog GS, Guillot J, Viscogliosi E. Pneumocystis oryctolagi sp. nov., an uncultured fungus causing pneumonia in rabbits at weaning: review of current knowledge, and description of a new taxon on genotypic, phylogenetic and phenotypic bases. FEMS Microbiol Rev 2006;30(6):853-71.

42. Shome SK, Batista AC. Occurence of Paracoccidioides brasiliensis in the soil of Recife, Brazil. Rev Fac Med Univ Fed Ceará 1963;3:90-4.

43. Negroni P. El Paracoccidioides brasiliensis vive saprotificamente en el suelo Argentino. Prensa Med Argent 1966;53:2381-2.

44. Albornoz MB. Isolation of Paracoccidioides brasiliensis from rural soil in Venezuela. Sabouraudia 1971;9:248-53.

45. Silva-Vergara M L, Martínez R, Chadu A, Madeira M, Freitas-Silva G. Isolation of Paracoccidioides brasiliensis strain from the soil of a coffee plantation in Ibiá, State of Minas Gerais, Brazil. Med Mycol 1998;36:37-42.

46. Grose E, Tamsitt JR. Paracoccidioides brasiliensis recovered from intestinal tract of three bats (Artibeus lituratus) in Colombia. Sabouraudia 1965;4:124-5.

47. Gesuele E. Aislamento de Paracoccidioides sp. de heces de pinguino de la Antárdida. In: Proceedings of the 4th International Meeting on Paracoccidioidomycosis; 1989; Caracas. Venezuela: 1989. Abstract B2.

48. Ferreira MS, Freitas LS, Lacaz CS, Del Negro GM, Aielo NT, Garcia MN, Assis CM, Salebian A, Heins-Vaccari EM. Isolation and characterization of a Paracoccidioides brasiliensis strain from dog food probaly contaminated with soil in Uberlândia, Brazil. J Med Vet Mycol 1990;38:253-6.

49. Franco M, Bagagli E, Scapolio S, Lacaz CS. A critical analysis of isolation of Paracoccidioides brasiliensis from soil. Med Mycol 2000;38:185-91.

50. Wanke B, Londero A. Epidemiology and Paracoccidioidomycosis infection. In: Franco M, Lacaz C, Restrepo A, Del Negro G, editors. Paracoccidioidomycosis. Boca Ratón: CRC Press; 1994. p. 109-20.

51. Simões LB, Marques SA, Bagagli E. Distribution of Paracoccidioidomycosis: determination of ecologic correlates through geographic information system and spatial analyzes. Med Mycol 2004;42:517-23.

52. Naiff RD, Ferreira LCP, Barreto TV, Naiff MF, Arias JR. Paracoccidioidomicose enzoótica em tatus (Dasypus novemcinctus) no Estado do Pará. Rev Inst Med Trop S Paulo 1986;28:19-27.

53. Naiff RD, Barreto TV. Novos registros de P. brasiliensis em tatus (Dasypus novemcinctus). Proceedings of the Congresso Brasileiro de Parasitologia; 1989; Rio de Janeiro, p. 197.

54. Bagagli E, Sano A, Coelho KIR, Alquati S, Miyaji M, Camargo ZP, Gomes G, Franco M, Montenegro MR. Isolation of Paracoccidioides brasiliensis from armadillos
(Dasypus novemcinctus) captured in an endemic area of paracoccidioidomycosis. Am J Trop Med Hyg 1998;58:505-12.

55. Bagagli E, Franco M, Bosco SMG, Hebeler-Barbosa F, Trinca LA, Montenegro MR. High frequency of Paracoccidioides brasiliensis infection in armadillo (Dasypus novemcinctus): an ecological study. Med Mycol 2003;41:217-23.

56. Macedo RCL, Lazera MS, Trilles L, Bulcão AS, Silva Jr NJ, Oliveira NA, Wanke B. Paracoccidioides brasiliensis - Infecção natural de tatus. Estudo em Serra da Mesa, Goiás, Brasil. In: Proceedings of VII International Meeting on Paracoccidioidomycosis. São Paulo, Brasil: Campos do Jordão; 1999. p.128.

57. Silva-Vergara ML, Martinez R, Camargo ZP, Malta MH, Maffei CM, Chadu JB. Isolation of Paracoccidioides brasiliensis from armadillos (Dasypus novemcinctus) in an area where the fungus was recently isolated from soil. Med Mycol 2000;38:193-9.

58. Corredor GG, Castaño JH, Peralta A, Díez S, Arango M, McEwen J, Restrepo A. Isolation of Paracoccidioides brasiliensis from the nine-banded armadillo Dasypus novemcinctus, in an endemic area for paracoccidioidomycosis in Colombia. Rev Iberoam Micol 1999;16(4):216-20.

59. Corredor GG, Peralta LA, Castaño JH, Zuluaga JS, Henao B, Arango M, Tabares AM, Matute DR, McEwen JG, Restrepo A. The naked-tailed armadillo Cabassous centralis (Miller 1899): a new host to Paracoccidioides brasiliensis. Molecular identification of the isolate. Med Mycol 2005;43(3):275-80.

60. Sano A, Tanaka R, Yokoyama K, Franco M, Bagagli E, Montenegro MR, Mikami Y, Miyaji M, Nishimura K. Comparison between human and armadillo Paracoccidioides brasiliensis by random amplified polymorphic DNA analysis. Mycopathologia 1999;143:165-9.

61. Sano A, Defaveri J, Tanaka R, Yokoyama K, Kurita N, Franco M, Coelho KI, Bagagli E, Montenegro MR, Myiaji M, Nishimura K. Pathogenicities and GP43 kDa gene of three Paracoccidioides brasiliensis isolates originated from a nine-banded armadillo (Dasypus novemcinctus). Mycopathologia 1999;144(2):61-5.

62. Hebeler-Barbosa F, Montenegro MR, Bagagli E. Virulence profiles of ten Paracoccidioides brasiliensis isolates obtained from armadillos (Dasypus novemcinctus). Med Mycol 2003;41:89-96.

63. Hebeler-Barbosa F, Morais FV, Montenegro MR, Kuramae EE, Montes B, McEwen JG, Puccia R, Bagagli E. Sequence comparison of the internal transcribed spacer regions and gp 43 in Paracoccidioides brasiliensis for patients and armadillos Dasypus novemcinctus. J Clin Microbiol 2003;41:5735-7.

64. Restrepo A, Baumgardner DJ, Bagagli E, Cooper CRJr, McGinnis MR, Lazera MS, Barbosa FH, Bosco SMG, Camargo ZP, Coelho KIR, Fortes ST, Franco M, Montenegro MR, Sano A, Wanke B. Clues to the presence of pathogenic fungi in certain environments. Med Mycol 2000;38:67-77.

65. Boily P. Individual variation in metabolic traits of wild nine-banded armadillos (Dasypus novemcinctus), and the aerobic capacity model for the evolution of endothermy. $\mathbf{J}$ Exp Biol 2002;205:3207-14. 
66. Purtilo DT, Walsh GP, Storrs EE, Gannon C. The immune system of the nine-banded armadillo (Dasypus novemcinctus Linn.). Anat Rec Philad 1975;181:725-34.

67. Howerth EW, Stallknechtt DE, Davidson WR, Wentworth EJ. Survey for leprosy in nine-banded armadillos (Dasypus novemcinctus) from the southeastern United States. J Wildl Dis 1990;26(1):112-5.

68. Eulálio KD, de Macedo RL, Cavalcanti MA, Martins LM, Lazera MS, Wanke B. Coccidioides immitis isolated from armadillos (Dasypus novemcinctus) in the state of Piauí, northeast Brazil. Mycopathologia 2001;149(2):57-61.

69. Theodoro RC, Candeias JMG, Araújo JP Jr, Bosco SMG, Macoris SAG, Padula LO Jr, Franco M, Bagagli E. Molecular detection of Paracoccidioides brasiliensis in soil. Med Mycol 2005;43(8):725-9.

70. Terçarioli GR, Bagagli E, Reis GM, Theodoro RC, Bosco SMG, Macoris SA, Richini-Pereira VB. Ecological study of Paracoccidioides brasiliensis in soil: growth ability, conidia production and molecular detection. (Submitted).

71. Richini-Pereira VB, Bosco SMG, Griese J, Theodoro RC, Macoris SAG, Silva RJ, Barrozo L, Tavares PMS, Zancopè-Oliveira RM, Bagagli E. Molecular detection of Paracoccidioides brasiliensis in road-killed wild animals. (Submitted). .

72. Costa EO, Diniz LSM, Fava-Netto C. The prevalence of positive intradermal reactions to paracoccidioidin in domestic and wild animals in São Paulo, Brazil. Vet Res Commun 1995;19:127-30.

73. Ricci G, Mota FT, Wakamatsu A. Canine paracoccidioidomycosis. Med Mycol 2004;42:379-83.

74. Farias MR, Werner J, Muro MD, Marques SA, Marques MEA, Franco MF, Ribeiro MG, Custodio CC, Condas LAZ, Bosco SMG, Bagagli E. Canine paracoccidioidomycosis: case report of generalized lymphadenitis. Rev Inst Med Trop S Paulo 2005;47(14):64.

75. Townsend CR, Begon M, Harper JL. Fundamentos em ecologia. 2nd ed. Porto Alegre: Artmed; 2006, p. 101-40.

76. Hutchinson GE. Concluding remarks. Cold Spling Harb Symp Quant Biol 1957;22:415-27.

77. Hutchinson GE, MacArthur RH. A theoretical ecological model of size distribution among species of animals. Am Nat 1959;93:117-25.

78. Macoris SAG, Sugizaki MF, Peraçoli MTS, Bosco SMG, Hebeler-Barbosa F, Simões LB, Theodoro RC, Trinca LA,
Bagagli E. Virulence attenuation and phenotypic variation of Paracoccidioides brasiliensis isolates obtained from armadillos and patients. Mem Inst Oswaldo Cruz 2006;10:331-4.

79. Theodoro RC, Bosco SMG, Araujo JP Jr, Candeias JMG, Macoris SAG, Trinca LA, Bagagli E. Dimorphism, thermal tolerance, virulence and Heat Shock Protein 70 expression in two cryptic species of Paracoccidioides brasiliensis. (to be submitted).

80. Mendes RP. The gamut of clinical manifestations. In: Franco M, Lacaz CS, Restrepo-Moreno A, Del Negro G. editors. Paracoccidioidomycosis. Boca Raton: CRC Press; 1994. p. 233-57.

81. Taylor JW, Turrner E, Townsend JP, Dettman JR, Jacobson D. Eukaryotic microbes, species recognition and the geographic limits of species: examples from the kingdom Fungi. Philos Trans R Soc Lond B Biol Sci 2006;29;361(1475):1947-63.

82. Ridley M. Evolução. 3rd ed. Porto Alegre: Artmed; 2006. p. 481-4.

83. Taylor JW, Jacobson DJ, Kroken S, Kasuga T, Geiser DM, Hibbett DS, Fisher MC. Phylogenetic species recognition and species concepts in fungi. Fungal Genet Biol 2000;31(1):21-32.

84. Matute DR, McEwen JG, Montes BA, San-Blas G, Bagagli E, Rauscher JT, Restrepo A, Morais F, Niño-Vega G, Taylor JW. Cryptic speciation and recombination in the fungus Paracoccidioides brasiliensis as revealed by gene genealogies. Mol Biol Evol 2006;23:65-73.

85. Matute DR, Sepulveda EV, Quesada LM, Goldman GH, Taylor JW, Restrepo A, McEwen JG. Microsatellite analysis of three phylogenetic species of Paracoccidioides brasiliensis. J Clin Microbiol 2006;44:2153-7.

86. Matute DR, Torres IP, Salgado-Salasar C, Restrepo A, McEwen JG. Background selection at the chitin synthase II (chs2) locus in Paracoccidioides brasiliensis species complex. Fungal Genet Biol 2007;44(5):357-67.

87. Dettman JR, Jacobson DJ, Turner E, Pringle A, Taylor JW. Reproductive isolation and phylogenetic divergence in Neurospora: comparing methods of species recognition in a model eukaryote. Evolution Int $\mathrm{J}$ Org Evolution 2003;57(12):2721-41. 